University of Louisville

ThinkIR: The University of Louisville's Institutional Repository

Electronic Theses and Dissertations

\title{
$5-2011$
}

\section{Pattern play : pieced works on paper.}

Gweneth A. Dunleavy 1954-

University of Louisville

Follow this and additional works at: https://ir.library.louisville.edu/etd

\section{Recommended Citation}

Dunleavy, Gweneth A. 1954-, "Pattern play : pieced works on paper." (2011). Electronic Theses and Dissertations. Paper 385.

https://doi.org/10.18297/etd/385

This Master's Thesis is brought to you for free and open access by ThinkIR: The University of Louisville's Institutional Repository. It has been accepted for inclusion in Electronic Theses and Dissertations by an authorized administrator of ThinkIR: The University of Louisville's Institutional Repository. This title appears here courtesy of the author, who has retained all other copyrights. For more information, please contact thinkir@louisville.edu. 
PATTERN PLAY:

PIECED WORKS ON PAPER

\author{
By \\ Gweneth A. Dunleavy \\ B.A., Carleton College, 1976 \\ M.A., University of Illinois at Urbana-Champaign, 1978
}

\author{
A Thesis \\ Submitted to the Faculty of the \\ College of Arts and Sciences of the University of Louisville \\ In Partial Fulfillment of the Requirements \\ for the Degree of
}

Master of Arts

Department of Fine Arts

University of Louisville

Louisville, Kentucky

May 2011 



\title{
PATTERN PLAY: PIECED WORKS ON PAPER
}

\author{
By \\ Gweneth A. Dunleavy \\ B.A., Carleton College, 1976 \\ M.A., University of Illinois at Urbana-Champaign, 1980
}

A Thesis Approved on

April 11, 2011

by the following Thesis Committee:

Thesis Director (Lida G. Gordon)

Clara A. Leuthart 


\title{
ABSTRACT \\ PATTERN PLAY: \\ PIECED WORKS ON PAPER
}

\author{
Gweneth A. Dunleavy
}

April 11, 2011

This thesis explores pattern juxtaposition using traditional American quilt block designs as the compositional basis for nine works pieced from screen printed paper. In the 1970 s, the quilt was celebrated for its apparent connection to Modernist design and was reclaimed by many feminist artists including Miriam Schapiro as a symbol of the exclusion of women's crafts from the arts hierarchy. The tension between these two perspectives continues today in the contemporary art quilt movement.

Block designs are tightly organized, relying on grids and repeated geometric forms to communicate multiple patterns simultaneously. Controlled placement of light and dark pieces can create effects like "counterchange," a frequently employed illusion which occurs when the mind shifts repeatedly between positive and negative shapes. Counterchange perplexes by suggesting that more than one pattern can occupy the same visual space. 


\section{TABLE OF CONTENTS}

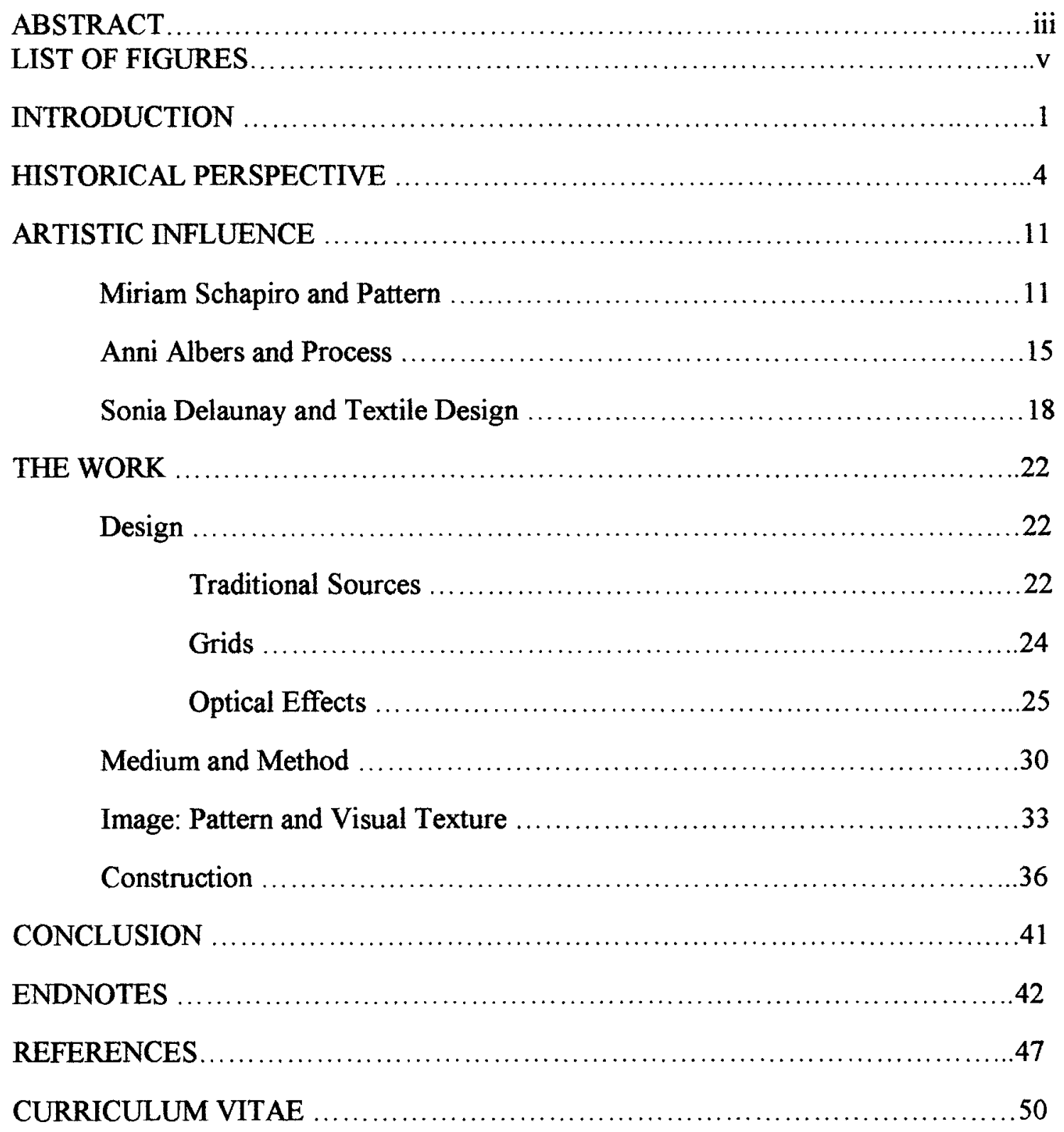




\section{LIST OF FIGURES}

$\begin{array}{ll}\text { FIGURE } & \text { PAGE }\end{array}$

1. Miriam Schapiro, Explode, 1972 ....................................... 15

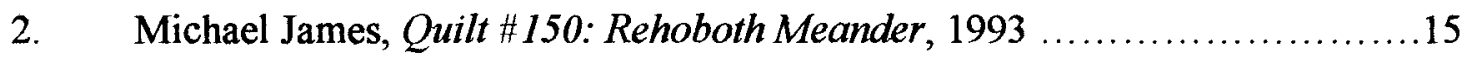

3. Sonia Delaunay, "Cubist" bed cover, 1911 ................................. 19

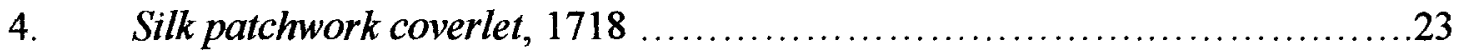

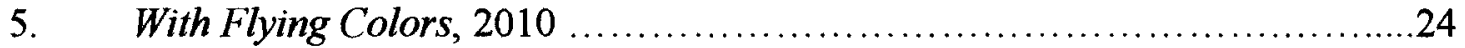

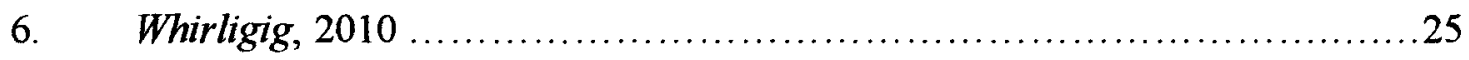

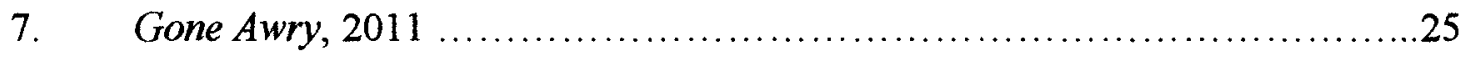

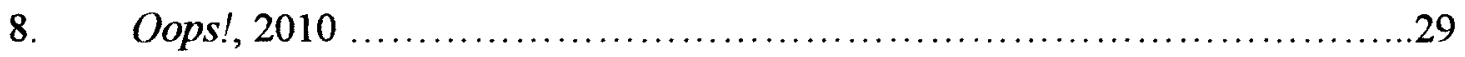

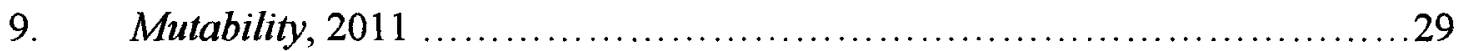

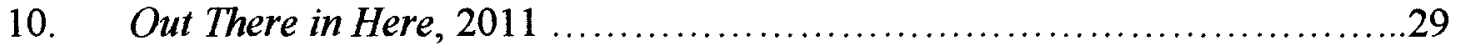

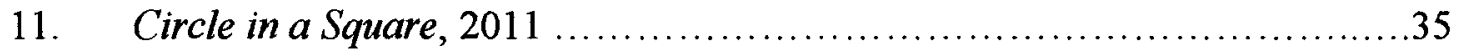

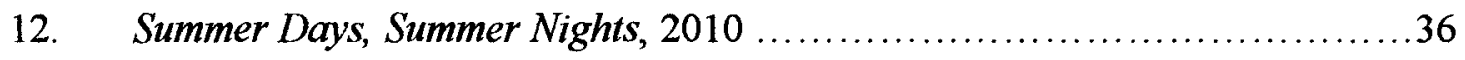

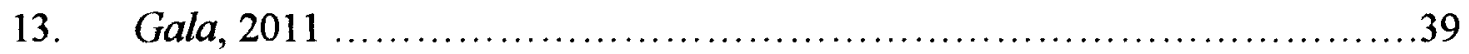




\section{INTRODUCTION}

This thesis explores visual effects of pattern juxtaposition using traditional American piecework designs as the starting point for contemporary experimentation. While references to the quilt as an historical and artistic form are inescapable, the works in this thesis, composed of handmade or screen printed paper, have none of the functional value of quilts made of stitched layers of fabric. A paper quilt offers neither warmth nor comfort, and paper as a material provides little of the tactile gratification of woven fabric. A glance, rather than a touch, is generally adequate to reveal that the surface of commercially produced paper is basically smooth and uniform. Unlike fabric which is flexible and forgiving, paper is stiff and stubborn: it shrinks but will not stretch; it tears easily and reveals every puncture mark; it flexes but will not fold without damage to its surface; it absorbs moisture and warps out of square or begins to disintegrate. Perhaps the most assertive quality of paper once it is formed into sheets is that it wants to be flat-mostly.

As both art form and hobby, quilting has enjoyed a remarkable renaissance over the past forty years. The contemporary art quilt is emerging as a credible mixed media genre challenging the exaggerated distinction between art and craft that for too long kept women's accomplishments in needlework and textiles low in the hierarchy of the arts. In short, this is a good time to be a quilt maker working in textiles. Why then have I chosen to make what look suspiciously like quilts with paper? 
It certainly wasn't a choice of convenience: I used many screen printing techniques that could have been as easily applied to fabric, and I might have minimized many construction challenges if I had been stitching through fabric rather than paper. One answer to the question of "why paper?" is that ink of the correct consistency, when applied to paper through a screen, generally stays and dries where it is put. Without the grain and texture of woven fabric, paper absorbs ink evenly, a characteristic that I rely on, particularly where two colors meet. Printing on paper allows me to bring together hard edges of pattern and color to create effects quite different from the subtle boundaries that can occur with more absorbent fabric. Paper takes less ink to print evenly and dries more quickly than fabric, allowing me to layer color more quickly. Paper also shrinks less than woven fabric so I can more accurately predict and measure how much material I will need to print for a whole project. Registration, or the process of printing each layer of color in an exact relationship to the others, is easier with stiff paper than with flexible fabric. Finally, ink which might stiffen and render fabric unwieldy actually strengthens paper and seals the surface, making it easier to handle during the construction process.

The most important reason I chose paper as my primary material was to eliminate the physical texture of fabric. While the collaged works are studies in pattern juxtaposition, the "scraps" themselves represent individual studies in visual texture. Screen printing is often considered a "flat" medium, appreciated for its graphic qualities, but through controlled layering, the screen printer can create the illusion of both depth and texture. One goal of mine was to tempt the viewer to reach out and touch the work in order to confirm that the apparent, low-relief texture of the surface was indeed illusory. In some printed designs, I purposely enhanced this illusion by mimicking the appearance 
of woven textiles. In my largest collaged piece, I tested the limits of the illusion further by incorporating strips of commercially printed fabric as well as screen printed muslin in small amounts proportional to the amount of screen printed paper. This modest effort at "trompe l'oeil" is intended to be a playful challenge to the viewer who must look longer and more carefully to sort out the paper from the fabric, the work of the artist from the work of a commercial textile mill.

Finally, paper appeals to me in its purest state as a material easily produced from natural fibers using processes that are derived from methods that date back thousands of years. Hand papermaking and screen printing both rely on simple tools- - primarily the screen--and both have strong connections to textile arts practiced by women for centuries. The genesis of the work for this thesis probably resides in a piece I composed nearly three years ago using paper I made from bleached cotton pulp then embossed in a manner reminiscent of quilt blocks. Although most of the screen printing I do is on commercially produced art paper (usually Rives BFK), I enjoy knowing that if I choose to do so, I can manufacture my primary material myself. Annie Albers, writing about design in 1947, pointed out that in the modern world, "the task of supplying the raw materials is largely in the hands of science," rather than in those of the craftsman who once "had the material in hand, not only figuratively, but actually, and it was his actual experience of wood, of fiber, of metal, that told him about his material. Its strength and its weakness directed him. ... Above all, the craftsman was free to follow the promptings of material ... to wherever it would lead him." ${ }^{1}$ More than any other material, paper has tempted me to follow. 


\section{HISTORICAL PERSPECTIVE: THE FEMINIST CASE FOR THE QUILT}

For the artist interested in two-dimensional design, traditional American pieced quilt blocks provide a virtual playground. A successful block design is a testament to the multiple problem-solving skills of its designer who manipulates color, value, and shape to balance positive and negative space and create a sense of movement across the overlaid geometric patterns that visually structure a quilt's surface. Maintaining rhythm through repetition and variation, the act of piecing a quilt requires the maker to utilize nearly every principle of two-dimensional design. Further, the act of quilting, or the use of stitched thread as line, enhances the work by imparting fine detail and low relief that is both visual and tactile, literally adding a third dimension to the finished piece and thus introducing the effect of light and shadow. As a student of both printmaking and surface design applied to fiber, I have come to regard the visual surface of a pieced quilt as the embodiment of every skill I hope to master.

Although I do not make functional quilts, the work I discuss in this thesis visually and structurally most resembles the category of work in fiber that is referred to as either the "art" or "studio" quilt. Following Jane Dunnewold's classification system for this diverse, mixed media category, I would describe my work as pieced paper quilts "inspired by traditional patterns and processes." ${ }^{2}$ American pieced quilts have strong associations with frontier life of the $19^{\text {th }}$ century, but the quilt also resonates for me as a 
symbol of early feminism's challenge to the art historical canon. Writing in 1973,

Patricia Mainardi was the first to argue that quilt making was not only an art form that

belonged to women but one that should be recognized as profoundly American:

Because quilt making is so indisputably women's art, many of the issues women artists are attempting to clarify now - questions of feminine sensibility, of originality and tradition, of individuality versus collectivity, of content and values in art - can be illuminated by a study of this art form, its relation to the lives of the artists, and how it has been dealt with in art history. The contrast between the utilitarian necessity of patching and quilting and the beautiful works of art which women made of it, and the contrast between the traditions of patchwork and quilting as brought to America and the quilts made here from colonial times to the present, give ample evidence that quilts are The Great American Art. ${ }^{3}$

Mainardi explained that the earliest American quilts were Crazy Quilts, constructed of odd-shaped bits of fabric randomly assembled in the manner of jigsaw puzzles.

Utilitarian and economical, these quilts have mostly worn out and few have survived.

Before long, however, women created no less economical but far more elaborate designs by uniformly cutting and patching scraps together, and by doing so, "women became the artists in a society in which their efforts were likely to be the only art that most of the populace saw, certainly the only art most of them possessed." ${ }^{\prime 4}$

That such pervasive art had been so long ignored was no surprise to Mainardi. In response to the Whitney Museum's ground-breaking exhibit Abstract Design in American Quilts in 1971, she pointed out that the male curator (Jonathan Holstein) valued quilts primarily because they "mirror in startling ways contemporary painting trends" with their superficial resemblance to the work of artists like Stella, Noland and Newman. In Mainardi's words, "what Holstein has done. . . is to turn history upside down and backwards. He has turned the innovators into the followers and used the quilts to legitimize contemporary formalist painting, while managing to dismiss these women as artists." 5 This inversion exemplified Mainardi's central concern that white male art 
historians had distorted the history of art so that "painting and sculpture done by white males over a five-hundred-year period in a small section of the world-namely western Europe-is the subject of intense and nauseating analysis," while textile and needlework arts of the world, "primarily because they have been the work of women, have been especially written out of art history." 6 Later critics have revealed another flaw in Holstein's argument by pointing to his exclusionary practice of privileging the pieced quilt over the appliqué quilt, an aesthetic judgment that ran counter to the traditional understanding of quilting history.

Regardless of Holstein's intentions, the Whitney show was hugely influential. Once Mainardi sanctioned the quilt as irrefutable evidence of the overlooked artistic contributions of "anonymous" females, Lucy Lippard noted that it quickly gained even greater symbolic value to contemporary women artists: "Since the new wave of feminist art began around 1970, the quilt has become the prime visual metaphor for women's lives, for women's culture. In properly prim grids or in rebelliously 'crazy' fields, it incorporates Spider Woman's web, political networking, and the collage aesthetic." 7

Lippard explained how this metaphor was to be perceived in the broader social framework of women's lives:

The quilt is a diary of touch, reflecting uniformity and disjunction, the diversity within monotony of women's routines. The mixing and matching of fragments is the product of the interrupted life. Quilts also incorporate the grid, a staple of women's art in the early days of the feminist art movement, symbolizing, perhaps, the desire to salvage order from domestic and other distractions. What is popularly seen as "repetitive," "obsessive," and "compulsive" in women's art is in fact a necessity for those whose time comes in small squares. Passive housekeeping differs from active homemaking. ${ }^{8}$

Echoing Simone de Beauvoir, Lippard argued that women are raised with "an exaggerated sense of detail, which extends from body to house to the objects it contains. 
The need to be 'busy' is often engendered by an ingrained emphasis on duty, cleanliness, and service." ${ }^{9}$ The fragmented, time-consuming process of quilting thus not only reflected the nature of women's housebound, repetitive tasks, but was particularly appropriate because rehabilitation--particularly of old clothing-- had always been women's work, determined as much by economics as biology. In essence much like mending, the "patchwork quilt originated in the careful patching of treasured antiques brought from the old countries. The crazy quilt - the most 'liberated' of traditional styles-was originally the most pedestrian, using every available scrap for warmth." 10

Even more than a way to preserve or create souvenirs, Lippard argued that "on a historical level, the quilt can be seen as a symbol of the feminist resurrection of our foremothers' lives." 11 To Miriam Schapiro, the quilt was no less than "the history of women, a receptacle of passions, attitudes, largesse, and anger. It is a reassembling process, which in itself may embody a solution to human problems. It is inspiration, a connection with self, the dogged will to make something extraordinary in the midst of family routine, a sense of wholeness, the wish to please, to succeed, pleasure in the act of working and knowing the power of "making." ${ }^{12}$ As a feminist artist who referenced quilts frequently, Schapiro created works based on femmage, her particular take on the ancient practice of collage, or pictures assembled from assorted materials. As Norma Broude pointed out, femmage as an activity had "been practiced for centuries by women, who used traditional craft techniques like sewing, piecing, hooking, quilting, and appliquéing. The extensive use of fabric swatches, patchwork and embroidery, both formal and iconographical elements in Schapiro's femmage, is part of her conscious 
effort to reestablish her connections with this older and-from the feminist point of view-more authentic tradition with which she, as an artist, identifies."

Schapiro noted another important characteristic of quilts: standards of excellence immediately reveal themselves. The craft of quilting is necessarily meticulous: "the skilled needleworker must be in command of the precise ordering of stitch to stitch, piece to piece, or else the entire work will be chaotic, the grand design ruined." ${ }^{14}$ This attention to detail can sometimes apply to works of enormous scale. Although some quilts are sized suitably for baby cribs, the visual control of quilt makers must often be maintained across a much larger field. Quilts are now displayed on king-sized beds, museum walls, or, as in the case of the AIDS Memorial Quilt, the National Mall in Washington D.C. Artist Jennifer Marsh of the International Fiber Collaborative is now collecting funds and quilt squares in large enough quantities to wrap a Saturn V rocket. ${ }^{15}$ Schapiro argued that such a highly developed "conception of order and geometry makes us remember women's earlier experiences cultivating the land. Eons ago, as hunting gave way to the domestic life separated from the kill, as the seasons acquired a new significance, women began to perceive themselves as those who would tame and provide for the interior landscape." ${ }^{16}$ Agricultural cultivation and geometry, both human inventions which confer some degree of control and certainty in the face of unpredictable natural phenomena, are evident in quilts where "pattern arranged in an enclosed space is divided and proportioned by geometry. In the counterchange between positive and negative shapes, we find the blueprint for endless variations on a theme." 17

As a basic artistic template, the quilt implies adaptability to change and provides infinite possibilities for experimentation, characteristics that have helped fuel the 
resurgence quilting has enjoyed over the past forty years. Referring to the art quilt movement in a recent lecture at the Carnegie Center of Art in New Albany, artist Jane Dunnewold noted that "this is a field made up predominantly of women, which is contrary to every art movement to date." Further, she explained:

Art quilting is like a huge organized religion, which is also unlike any art movement to date. The Studio Art Quilt Associates is an example of women artists taking matters into their own hands to develop the venues that are desired and needed in order to progress. Without being overt, this is a socio-political statement. Art quilters are no longer waiting to be invited into the mainstream art world. They are creating venues for parallel play while devising efforts to go mainstream. This has so far, been relatively frustrating because the art world is territorial and also traditional in the sense of how the "rules" work. ${ }^{18}$

Equally frustrating is the fact that quilt makers are divided among themselves over the aesthetic value of their work. In String, Felt, Thread: The Hierarchy of Art and Craft in American Art, Elissa Auther cites the work of Susan E. Bernick, a philosopher of art whose work has concentrated on the changing aesthetic status of quilts after 1970:

Bernick divides quilt making into three distinct "cultures" in "descending order of social legitimacy"; that of the "art quilter," that of the "feminist quilter," and that of the "traditional quilter." None of the three quilt cultures, according to Bernick, can lay claim to fully describing the meaning and value of quilts, and each generates its own "narrative of certification" concerning the quilt as art, which reflects the varying social interests and aesthetic orientations of the contexts of production in the high art world, the women's art movement, or the traditional quilting community, respectively. ${ }^{19}$

Further, not all observers share Dunnewold's confidence in the secure future of the art quilt. Writing in Surface Design in 2010, Michael James, a painter turned quilter and professor of textiles, notes the "failure, thus far, to grow a vigorous retail market and a strong list of serious and committed collectors." Additionally, he points out that the most innovative ideas in art quilts are currently being expressed by non-American artists. He speculates that the workshop industry, the American propensity to bond with others who think similarly, and a "consciousness of and respect for tradition and the role quilts have 
played in women's lives" may all contribute to the "seen it before' predictability" of American art quilts. ${ }^{20}$

Thirty years ago, Rozsika Parker wrote that "in the hierarchy the arts of painting and sculpture enjoy an elevated status while other arts that adorn people, homes or utensils are relegated to a lesser cultural sphere under such terms as 'applied', 'decorative' or lesser arts. This hierarchy is maintained by attributing to the decorative arts a lesser degree of intellectual effort or appeal and a greater concern with manual skill and utility." ${ }^{21}$ Today, post-modernist sensibility no longer supports a hierarchy that defines "women's work" as decorative craft of substantially less significance than the "high" art of modernist painting, but as Bernick suggests, problems of definition persist. What remains essential to both the interpretation and practice of contemporary art is the spirit of critique and inquiry, as Ann Newdigate, a British textile artist and feminist explains:

Acknowledging and respecting the value of difference - including one's owninvolves many intersecting points of incompatibility that, like slow, old tapestry, do not make for the flawless fabric of a single official history written from the perspective of a white, heterosexual, male subject position. For me, now, it does not matter whether what I do in my studio complies with a minor or a major language - whether it is kinda art or sorta textile. Whenever I feel a definition coming on, I try to remember to ask myself 'Who constructed the definition?', 'Who needs the oppositional distinctions and is going to benefit from them?', and 'Why should I comply with those codes and conventions?'22

As Jane Dunnewold confirms, "the most significant reality is that it still comes down to one artist, in one studio, becoming intimately aware of her own process and preferences; actualizing her own quest for meaning and/or creative growth, and then having the courage to pursue it independent of others. We must do whatever we can to honor that impulse."23 


\section{ARTISTIC INFLUENCE}

It is impossible to cite every visual influence on my work, but I know I have developed much of my visual aesthetic by looking at painters, especially those who followed Cezanne. In matters of composition, color choice, and layering technique, I am particularly indebted to the paintings of Post-Impressionists, Cubists, Abstract Expressionists, and Color Field painters. For patterning, I find helpful sources in the work of Matisse and Klimt as well as members of the Pattern and Decoration movement

like Kim MacConnell and Robert Kushner. Because I am interested in the geometry underlying design, I tend to find inspiration in abstraction more often than realistic illusion.

Theoretically, however, I can point to more specific influences on the way that I think about my art and the concepts that govern my choices as an artist. For help understanding what it is that I do, I find I often turn to women.

\section{Miriam Schapiro and Pattern}

Writing about "The Artist and the Quilt Project" (initiated in 1975 as a celebration of the United Nations "International Year of the Woman") which paired female artists who provided designs with needlewomen who then figured out how to turn the designs into quilts, Lucy Lippard noted that "within the context of feminist opposition to patriarchal values and to the colonization/destruction of other cultures, the quilt form offers a provocative vehicle for outreach," one that could be used to "examine and close 
artificial gaps between high and low culture, to reintegrate art and social life. " 24 To

Lippard, the collaborative quilts, as new hybrids, were "in a sense, collages of previous

art attitudes" that exemplified Raymond William's concept of residual, dominant, and emergent cultures:

"Residual" would be the history of the quilt-the stubborn legacy of "anonymous" women from all our pasts; "dominant" would be the component by which art is now defined and which makes these contemporary quilts verge on high culture, while others do not, because the women who made these have names, even "big names." And the "emergent" element is part of a reskilling process that involves social change as well as exchange-a major factor in the development of a cultural democracy. ${ }^{25}$

Among the "big names" who participated were Lynda Benglis, Faith Ringgold, Joyce Kozloff and Miriam Schapiro.

Feminist art historians often focused on the challenge that Schapiro's work posed to the conventional dichotomies of "high" and "low" culture, fine art and craft. As

Norma Broude wrote:

Like Matisse and Kandinsky before her, Schapiro has taken the product of craft and transported it, through contextual change, into the realm of high art. But with one crucial difference. For when Schapiro incorporates craft into a high art context . . . she does not treat her sources as borrowings to be transformed. Unlike Matisse and Kandinsky, she does not transform her materials in an effort to efface their original character. Rather, she reveals them-perhaps fully for the first time - as objects of aesthetic value and expressive significance. What more powerful and meaningful embodiment of the human spirit (to borrow the language of Kandinsky) might we ask for than these artifacts, which express not only the lives and skills and tastes of women but also their undauntable will to create? ${ }^{26}$

Janet Berlo described Mary Cassatt and Me (1974) in similar terms:

The Cassatt image she chooses is significant: a young woman gazes into a mirror. The message is self-scrutiny, self-reflection. What does a woman artist see when she looks at herself and looks at the art of other women-reflections and affirmations of her own art? Framing this central image are successive borders of fabric collage, the outermost one a traditional quilt block pattern. This celebrates 
the work of anonymous textile artists whose work was traditionally outside the mainstream of "high" art.

In a positive review of Rozsika Parker's The Subversive Stitch, Tamar Garb argued that Broude's defense of Schapiro raised "certain theoretical problems which are central to recent discussions both of women's art practice and of the hierarchical 'splittings' which definitions of Art and Craft have come to produce." The difficulty resides in "the entrenchment of the Modernist paradigm and the exclusive history it has constructed for itself," a history that has consistently ignored the significance of women's production. ${ }^{28}$ Garb proposed that feminist art needed to assert significance on its own terms by remaining outside the Modernist tradition and establishing an independent history and set of criteria.

In "Betraying the Feminist Intention: The Case Against Feminist Decorative Art" written in 1979, Donald Kuspit noted some of the same theoretical problems as Garb, but worried that the history some feminists were constructing was already becoming conservative and moribund: "Feminist decorative art, more particularly but not exclusively pattern painting, is an example of feminist thought which has willingly emerged from its critical element, and as such signals the dawn of an era of authoritarian feminism, i.e., a feminism which means to entrench itself, to become as 'corporate' and establishment as the masculine ideology it presumably means to overthrow."29 Finding proof for this argument in what he called the "deliberately fixed" and "uncritically presented" pattern, Kuspit declared that "the belabored aestheticism" of Kozloff and Schapiro was co-opting a more genuine, feminist avant-garde: "feminist modernism, meaning to bespeak feminist sensibility, renders it as authoritarian as all narcissistic concepts are: this authoritarianism is exemplified in the rigid absolute pattern."30 
Minimally, Kuspit overstated the importance of the Pattern and Decoration Movement which never claimed to be the only emerging feminist art, but I find his insistence on the rigidity of pattern equally problematic. A more convincing analysis of pattern is offered by Oleg Grabar in Mediation of Ornament (1992), one noted by Alexandra AndersonSpivy while writing on Robert Kushner in 1997. In a series of lectures on Islamic art, Grabar "proposed that formal elements considered to be the mere garnishments of high art-abstract patterns, repetitive forms drawn from nature, motifs dictated by fashionare, in fact, its crucial expressive elements." Further, Grabar finds evidence that "decorative patterns . . . are all vehicles of pleasure as well as the only means by which any art can stake a claim for universal appeal." ${ }^{31}$ Conferring pleasure has rarely been the goal of authoritarian ideology.

Additionally, Kuspit's analysis missed the fact that much of the vitality of Schapiro's work depends on the contrast between pattern and abstraction, a point well made by Linda Nochlin: "Perhaps nowhere are the claims and counterclaims of hardedge, expressive brushstroke and patchwork made more explicit than in the aptly titled Explode, where the angular fragments of brilliantly patterned textile literally burst out upon us from the light-colored, red-framed 'picture space' in an aggressive assault upon the actual space of the world, a kind of patchwork liberation" ${ }^{32}$ (see Figure 1). This dynamic tension remains compelling, and informs the contemporary art quilts of Michael James, whose choice to abandon painting in favor of quilt making served "as a reminder that the language of quilts was not, in fact, simply a female idiom" ${ }^{33}$ (see Figure 2). Contrary to Kuspit's forebodings, neither feminist art nor feminist theory remained static. 
As both evolved to tackle the fundamental questions posed by first-wave, feminist art historians, Linda Nochlin again sounded a voice of reason:

Not all women artists are feminists; not all feminist artists wish to incorporate their feminist identity into their art works, and, certainly, even if some of them do, none will do it in the same way. Miriam Schapiro's collages are unique and deeply personal statements: they are by no means programmatic or didactic in their intentions or their effects. They do, however, in their splendor and novelty, suggest one of the many possible modes of interaction between feminism and art, in which the woman artist's consciousness of her identity can function with the same force and validity as did the Abstract Expressionists' awareness of their identity as Americans in the forties and fifties. ${ }^{34}$

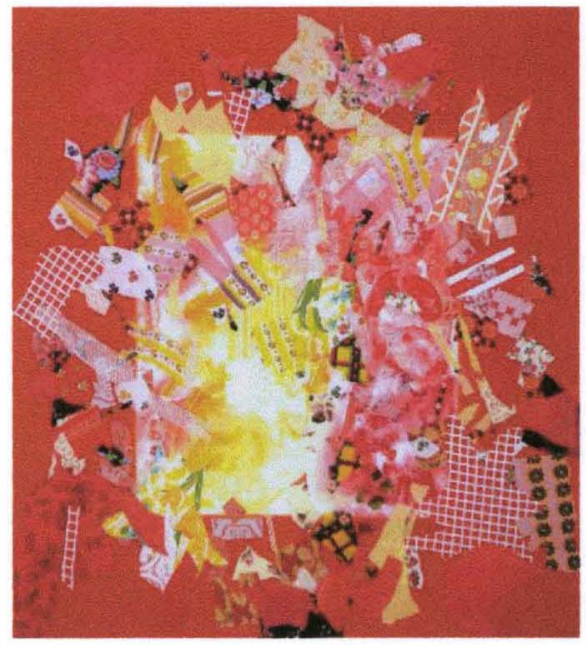

Figure 1: Miriam Schapiro, Explode, 1972 CMiriam Schapiro

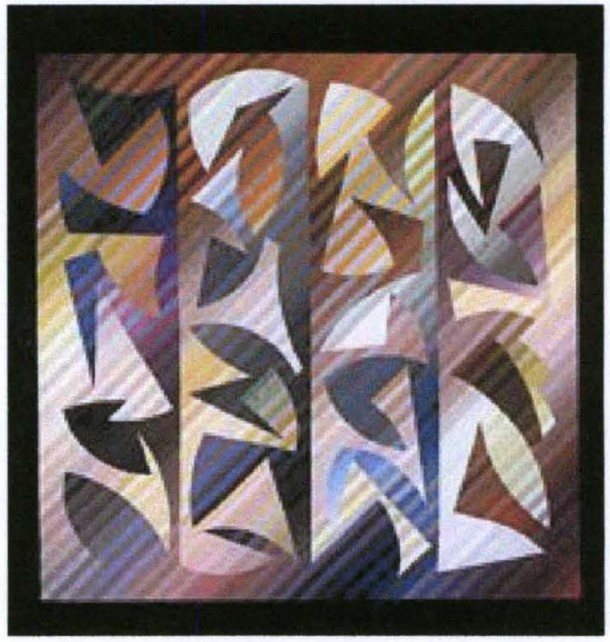

Figure 2: Michael James, Quilt \# 150: Rehoboth Meander,1993 C Michael James

Splendor and novelty are just two of the characteristics that cause Schapiro's

work to resonate with me. Not only do I appreciate her riffs on the traditional quilt, I also love her bold use of color, the scale of her work, her interest in Japanese textiles as displayed in works like Anatomy of a Kimono, and her playful experiments with borders and frames. Although Schapiro was by no means single-handedly responsible for increasing the visibility of quilts, she was able to incorporate quilting references into her work without erasing the quilt's connection to real women's lives. As Elissa Auther points out, Schapiro "may be criticized for her reputation as an innovator through the 
incorporation of other women's traditional fiber-craft into her work, ${ }^{35}$ but her work is an affirmation rather than a negation of women's lives and history.

\section{Anni Albers and Process}

Anni Albers quite reasonably pointed out that the way to gain confidence and independence as an artist was to come to grips with material, "the most real thing there is." Stating that all art work can be understood "as the transformed wish for stability and order," Albers argued that "material, that is to say unformed or unshaped matter, is the field where authority blocks independent experimentation less than in many other fields. Free experimentation here can result in the fulfillment of an inner urge to give form and to give permanence to ideas, that is to say, it can result in art." 36 In my effort to bring differing media together in new ways, Anni Albers has proven to be an increasingly important guide. Not only does she have a highly developed sense of design, as a textile artist and educator who switched to screen printing later in her career, Albers "contributed to the breakdown of distinctions between media that was carried through by subsequent artists both inside and outside the crafts world." 37

Further, Albers emphasis on materiality points to one of the things that most appeals to me about art making: the tactile gratification of learning through my hands. In Abstracting Craft, Malcolm McCullough points out that in our technological, serviceoriented society, "hands are underrated. Eyes are in charge, mind gets all the study, and heads do all the talking. Hands type letters, push mice around, and grip steering wheels, so they are not idle, just underemployed." He continues:

This is a sorry state of affairs, for hands can contribute much to working and knowing. By pointing, pushing and pulling, by picking up tools, hands act as conduits through which we extend our will to the world. They serve also as conduits in the other direction: hands bring us knowledge of the world. Hands 
feel. They probe. They practice. They give us sense, as in good common sense, which otherwise seems to be missing lately. ${ }^{38}$

McCullough is also aware that hands communicate in a way that machines do not, and identifies what, for me, is an extremely important part of the process of making art regardless of medium: the development of craft. In McCullough's terms, "the way of hands is personal, contextual, indescribable. Little can surpass the hands in showing that we know more than we can say. Psychologists and social scientists have studied this inarticulable knowledge extensively, and they have many names for it: operative, actioncentered, enactive, reflection-in-action, know-how. The most common word is skill."39 Skill is acquired through practice, a concept that pleases me because I can't rely on innate ability when it comes to art. Additionally, I like the idea that my hands, too long underemployed, now have some creative work to do.

Albers is also significant for me because she designs according to the grid, the same organizing principle evident in quilts, much Modernist painting, andunconsciously at first-- much of my work. Without recognizing that I was choosing to do so, I gravitated towards grids, not exclusively, but consistently. When I realized the extent to which I rely on the grid to compose an image, I assumed that it was probably a naïve or convenient form of visual conception, one used by novice artists. Hannah Higgins, however, has persuaded me that the grid is a powerful, inescapable concept, one that I have been choosing purposely to help articulate an idea that has been increasingly dominating my conscious thought, that the narrative of a life is not necessarily best told in a linear way and that the reality we create-one that is apparently organized, rational, causal, and secure-is actually an elaborate fiction we engage in to avoid being 
overwhelmed by the random, intuitive, unpredictable, and terrifying forces that actually motivate life on earth. As Higgins proposes,

The experience of chaos as chaos requires an organizing principle, a frame of reference through which it is perceived as chaotic relative to something that is not. What's less chaotic than the standard, orderly, ordering grid? In contrast, that which is experienced as chaos could portend an emergent but not yet schematized grid, a decomposing grid, a twisted grid, the interaction of one grid with another, or a truly chaotic circumstance. ${ }^{40}$

Alber's work, taken in totality, poses some of these same dichotomies:

While it would be difficult to claim for Anni Alber's prints and drawings the originality and beauty of her weavings, it is clear that the prints arise from similar conflicting impulses. First among these is the need to control free and sensuous expression through the imposition of predictable form and process. In weaving there are the horizontals and verticals of the threads and the evocative textures and patterns of the surfaces. In prints there are the discipline of the grid and the mechanically deposited layers of color that vie with the impulses of the hand. ${ }^{41}$

To Higgins, grids help us make sense of chaos; to Albers, design serves a similar function as a method of visual organization that helps us understand nature. Albers notes that in practical matters like agriculture, humans tend towards the "intrinsically geometric," and considers the goal of all design to be "implicit lucidity, a considered position, a reduction to the comprehensible by reason or intuition in whatever we touch (confusion always gets a negative rating)." ${ }^{42}$ Art occurs when designed form becomes "the carrier of meaning that takes us beyond what we think of as immediate reality." Art shares with nature a quality of mystery, but "nature," says Albers, "shows herself to us only in part. To reassure us, art tries to show us a wholeness that we can comprehend."

\section{Sonia Delaunay and Textile Design}

Like many of the artists I find most interesting, Sonia Delaunay was multitalented and worked across media. Not only was she a Cubist painter, she designed textiles, fashion garments, and sets for the theater. Her textiles "championed geometric 
design so that she could liberate cloth from conventional uses." Virginia Troy explains that multi-functionality allowed Delaunay "to use textiles as an element in the total work of art, one that was not static but rather functioned spatially, to be activated by the movement of the cloth itself and the illusion of movement created by the colours and patterns in relationship to other objects, a phenomenon she referred to as simultaneity." 44 As the copy for a current exhibition of her work at the Cooper-Hewitt National Design Museum explains, “A trademark of Delaunay's work is the sense of movement and rhythm created by the simultaneous contrasts of certain colors." 45

Given my interests, it seems particularly fitting that Sonia Delaunay's Cubist achievements were launched by a baby blanket (see Figure 3). As one biographer explains, the stimulus to alter her work began with the birth of Delaunay's son:

When Charles was born he had an Empire bed. She created for it a patchwork quilt (now in the collection of the Musée National d'Art Moderne in Paris) out of fabric remnants, in a style she remembered from the handiwork of Russian peasant women. Friends who saw it exclaimed that is was Cubist, though Sonia had put it together completely spontaneously. As she continued in other works to use this technique, art critics saw in it a kind of "geometrization" of forms and a melody of colours which presaged the work she produced in the years that followed. In other words, the patchwork quilt led directly to her break with perspective and naturalism. ${ }^{46}$

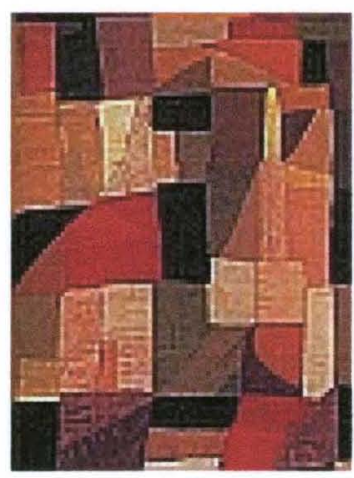

Figure 3: Sonia Delaunay, "Cubist" bed cover, 1911 
Not only am I drawn to Delaunay's use of color, her work is representative of another influence on me: textile design. Although many artists have experimented with textile design and whole artistic movements have recognized the ability of textiles to bridge the art and craft divide, most textile designers are anonymous. ${ }^{47}$ As Susan Meller states, "Theirs is the kind of art in which the personality and the ideas of the maker recede so far into the background as to disappear." 48 Furthermore, textile designers, focused on repeating patterns, unashamedly draw their motifs from any culture or historical period to recycle images that have been around for decades or millennia. Meller further notes that "in the long history of image making, the value of originality is a fairly recent idea, and a Western one at that. It is only for some few hundred years now that we in the West have valued originality and novelty above all things in art. In fact, we have equated it with freedom. Fabric patterns go back to humanity's earliest times and belong to a much older tradition of symbols, where originality is not an issue." 49

Textile design, or color and pattern applied to the surface of woven cloth, was dependent on printing methods long before the development of commercial textile mills. Sample books of printed pattern designs have been in existence since 1524. First intended for amateurs, these books "were by the $17^{\text {th }}$ century influencing the professional design and production of textiles." ${ }^{50}$ Hand block printing, the earliest method of printing cloth, was succeeded by stenciling, probably a consequence of the reopening of Japan in the 1860s. Screen printing, a convergence of new technologies, developed soon thereafter. The forebear of the screen used in printmaking today was patented in the United States in 1887 ; other patents for improving the even delivery of color-notably the squeegee-followed shortly so that "screens finally came into their own for hand- 
printing in the 1930s." ${ }^{\text {51 }}$ As inexpensive, mechanical methods of screen printing developed in the commercial textile industry, screen printing became an experimental technique adopted by artists, notably Harry Gottlieb and others commissioned by the W.P.A.

Prior to mechanical screen printing, roller printing was the primary method of printing textiles, mostly in small all-over designs, the strength of machine printers. With the rise of cotton as an inexpensive, "people's" cloth, a greater degree of obsolescence was built into the textile industry than when sturdier linens dominated the market. Interestingly, this had a direct relationship to the development of quilting methods:

Both the relatively low resistance to wear and "plainness" of cottons contributed to vivid and varied uses of appliqué, patchwork and quilting around the world. Quilting, in particular, lent great strength to the completed work. The anonymity of mass-produced cotton cloths and yarns was nullified by these creative interventions, which remained characterized by home production, whether San Blas molas, Rajasthani rally, Indo-Chinese reverse appliqué, Egyptian appliqué tent hangings, or the distinctly different patchwork of Bangladesh (kantha) and North America. ${ }^{52}$

Continuing in the multi-talented tradition of Sonia Delaunay, Kaffe Fassett is just one example of a contemporary textile designer who also makes quilts from the cloth he designs. Additionally, many practitioners in the art quilt movement dye and print their own fabrics and innovative companies like Spoonflower.com allow even design amateurs an inexpensive way to create printed fabrics from their own digital images. Whether conscious of their sources or not, these artists all draw inspiration from extant textile designs. As Mellor explains:

It's as if textile patterns were an immense library of images waiting for us to attach meaning to them, or as if Jung's idea of the collective unconscious were made literal in this storehouse of shapes. We love to see these motifs, love to see them so much that we cover everything with them, to the point where they become commonplace and disappear- they hide in the light. ${ }^{53}$ 


\section{THE WORK}

The exhibit consists of nine pieced works ranging in size from 24 " $x 24$ " to 54 " $\mathrm{x}$ 72". All are composed of cut geometric shapes of handmade or screen-printed paper stitched to commercially produced paper or canvas. Although much of the printing occurred at an earlier date, the stitched compositions are recent: four pieces were constructed during 2010; five were completed in 2011.

\section{Design}

The design of each piece is highly organized, relying on the geometry of traditional quilt blocks and grids to emphasize the interesting optical effects produced by placing several blocks together.

Traditional Sources: The starting point for each composition is a traditional pieced quilt block. Relying primarily on The Quilter's Block Bible (2003) by Celia Eddy, I tended to choose designs that were published in the late $19^{\text {th }}$ or early $20^{\text {th }}$ centuries. In all likelihood, the designs preceded their publication by decades or even centuries. As Eddy notes, "the block has been around for a very long time in relation to quilt making. It was certainly a feature of English patchwork from early times. This has been proven by the earliest dated example, a silk coverlet dated 1718, measuring 108 inches square and worked entirely in four-inch blocks, including geometrical designs, human figures, plants, birds, and animals" ${ }^{54}$ (see Figure 4). 


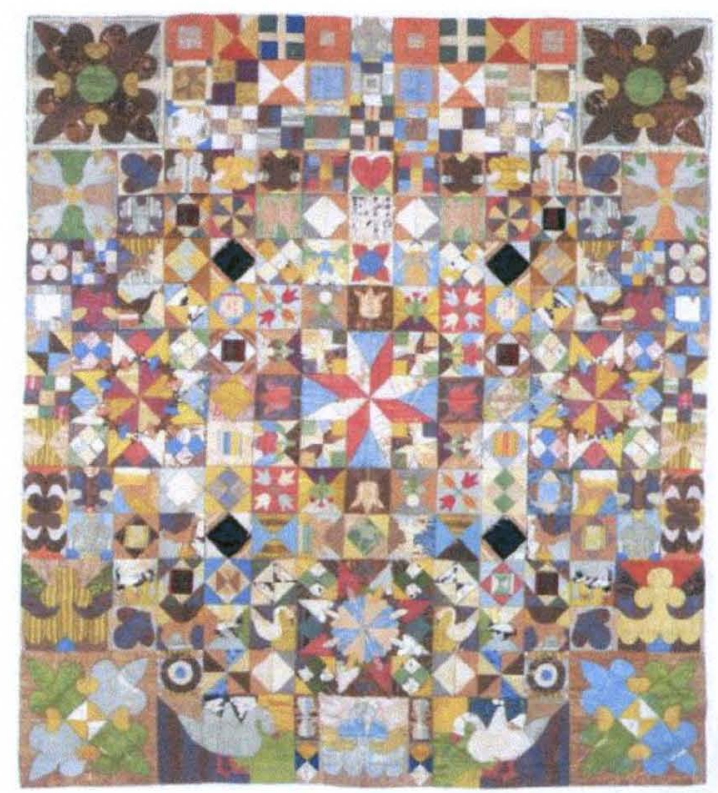

Figure 4: Silk patchwork coverlet, 1718

Preserved in the Quilt Museum in York, England, the coverlet contains pieces of over 120 different fabric designs, most from dress fabrics that show previous signs of use.

In contemporary quilting encyclopedias, there are over 4,000 documented block designs which are usually grouped according to the way that they are drafted. The blocks I used fit into well-known categories such as four-patch, nine-patch, and log cabin. In almost all cases, my choice of block design was governed by two concerns: the degree of difficulty I anticipated I would encounter during cutting and piecing, and the final size of the work. The latter was determined by the dimensions of the block and by the number of blocks I chose to manufacture to achieve the overall effect I desired. Occasionally, this decision depended on the amount of printed paper I had available in a particular color or design, but most often, I decided on the final size first and produced whatever screen printed paper I needed to complete it.

Most quilt block designs come with a history, and sometimes more than one name. Although I found this interesting, with only one exception, I was more influenced by geometry than nomenclature or history when I began working with a design. The 
exception was Barbara Fritchie Star, the block I used as the basis of With Flying Colors. Although the story may be apocryphal, I responded to the spunky character of its subject, who at the age of 95 became a heroine of the American Civil War by refusing to lower the Unionist flag when her hometown (Frederick, Maryland) was invaded by the Confederates. It seems pretty clear to me now that I must have had flags in mind when I chose the patterns and color scheme of that piece (see Figure 5).

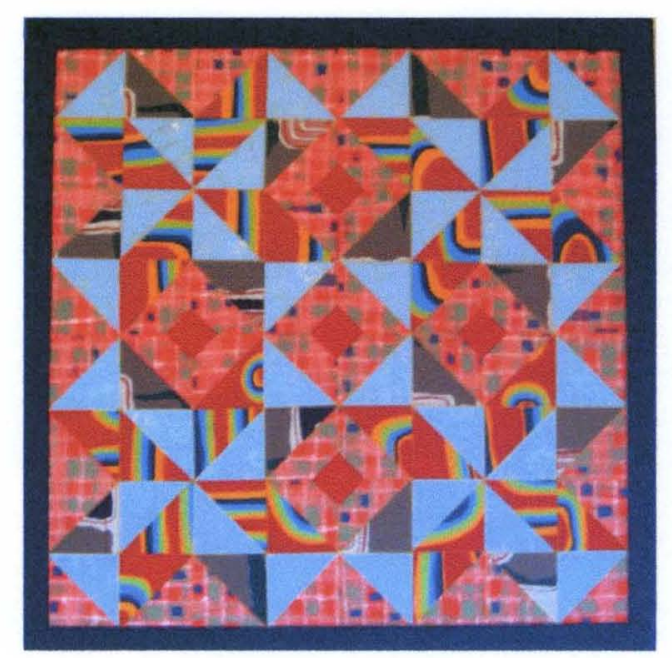

Figure 5: With Flying Colors, 2010

Grids: All block designs are drafted according to grids, most commonly either square or isometric. The isometric grid is based on 60-degree diamonds and tends to produce designs that are pieced along diagonal lines such as many of the star patterns. I found it particularly difficult to manipulate flat, stiff paper through a sewing machine to stitch long diagonal lines; for this reason, I chose to work exclusively with patterns drafted on square grids. The grid underlying each design becomes apparent when trying to break down the composition of a block; for example, any block in the nine-patch category is designed according to a $3 \times 3$ grid of nine squares. Squares in a grid may contain the same information but be oriented in different directions so that the squares 
reverse or mirror one another to create a unified block design. Although the blocks look different, many of the designs I chose are based on grids of three-inch squares.

Grids also emerge when blocks are connected to one another. The repetition of a block communicates the concept of a grid whether or not a grid is an intentional component of a block's design. Because the blocks are composed in squares which are then joined with visible lines of stitching, the grid is always an element that visually structures the surface of a traditionally pieced work. Whirligig, based on the four-patch block Clay's Choice, is an exploration of the dynamic between the grid and the design it helps to structure. When the block's design is fragmented, the grid is the most evident structural device of the piece; when the block is whole, the grid supporting it disappears (see Figure 6). Similarly, in Gone Awry, the grid appears asymmetrical when it is actually the stable organizational element. The focal point is off-center, and the grid appears to be discontinuous only because the orientation of the 3 " squares changes in each of the four sections of the piece (see Figure 7)..

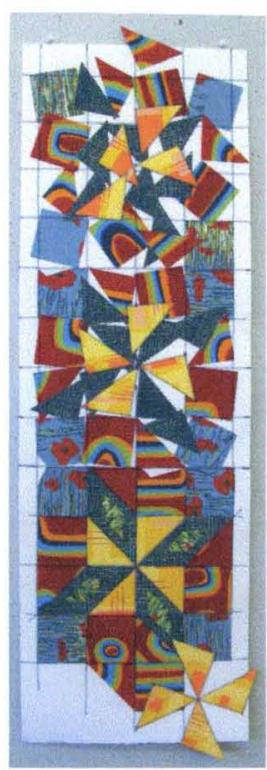

Figure 6: Whirligig, 2010

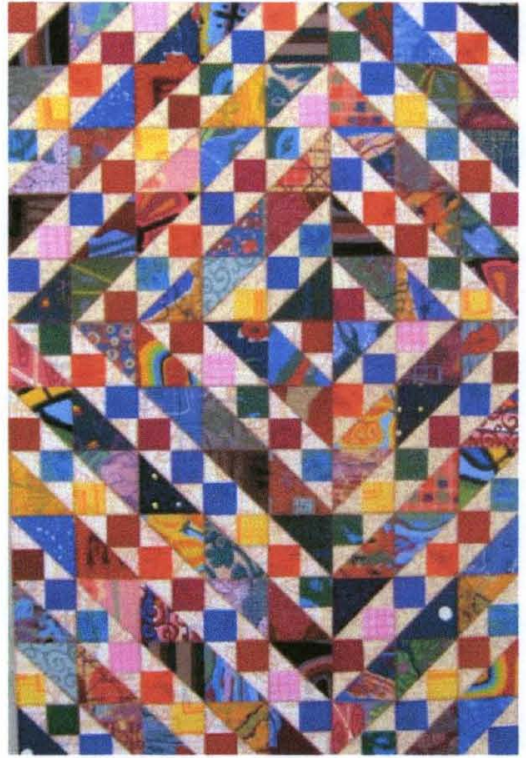

Figure 7: Gone Awry, 2011 
Optical Effects: In Quilting Illusions, Celia Eddy lists the six most common ways that block designs can be used to create optical illusions: perspective and 3-D, circles, grids, interlacing, counterchange, and transparency. ${ }^{55}$ Not all blocks will create optical illusions, but some of the ones that do are among the best known of all quilt block designs, such as Tumbling Blocks which relies on the same kind of optical illusion that informs the work of M.C. Escher. Playing on the conventions of perspective, Tumbling Blocks portrays cubes, ambiguously both concave and convex, that appear to move from one state to the other. In The Visual Nature of Color, Patricia Sloane explains that optical illusions work by defeating ordinary expectations; in this way, "they are less illusory than they are parallels to verbal puns, in which a single word is susceptible to multiple interpretations." 56 She notes that "the defining nature of optical illusions is not the illusoriness attributed to them. Each illusion consists of a visual or graphic form that contradicts commonplace intellectual expectations. Most of the expectations are guided by our strange conceptions of reality, the suprareality in which everything remains the same although this is not what we see." ${ }^{57}$ Sloane further suggests that optical illusions "teach visual lessons we do not want to learn" and posits that, contrary to the common understanding that the brain corrects the eye's shortcomings, it's quite possible that "the eye is seeing correctly but the brain is not thinking very clearly." 58 According to Sloane the problem is our reluctance to come to terms with visual space, or the space of flat surfaces, which is unique: "As optical illusions teach, visual space cannot be understood in terms of rules that apply to three dimensional space and often fails to conform to our conception of three-dimensional reality. Visual space is a two-dimensional world with a reality of its own." 59 Applying these ideas to the kinds of optical illusions achieved by 
quilters, Laura Fisher explains that "as one tries to focus on a particular area to gain visual stability and to determine the pattern, the visual system will become fatigued, and there may seem to be: a sensation of shifting or overlapping images; a sensation of ambiguity in the figure-ground relationship; a visual tension which makes it hard to separate figure from ground; or a change in the orientation of the pattern which causes the viewer to read different spatial effects." 60

Speculating about the origin of geometric patterns that create illusionary effects, Fisher cites the influence of Islamic culture which reached the highest level of ornamental art based on geometry. Islamic designs were evident in Europe by the $13^{\text {th }}$ century, appearing in the intricate patterns of paving stones. In fact, Fisher states that the most pervasive source of geometric, illusionary patterning was probably architectural ornamentation and woodcraft: "Ancient motifs from many cultures-Greek, Roman, Etruscan, early Christian, Middle Eastern, Moorish, Islamic, and Oriental-are echoed in quilt patterns. As early as the $5^{\text {th }}$ century, B.C., glass mosaics and architectural ornaments in wood, stone, and metal evinced elements of design that were optical illusions." ${ }^{61}$ Closer to home, Fisher points out that "a quilter needed to look no farther than her window, where light casting shadows, filtered by lace curtains or architectural ornaments, left a geometric image that could be translated into cloth. Natural objects like the growth rings of trees, the planes of a crystal geode, or the tracery of a snowflake could be equally suggestive. Patterns abounded in the landscape, modulated by light and ready for interpretation in fabric by a creative person." 62

Although I experimented a bit with perspective and 3-D in Out There in Here, a variation of Attic Windows, the optical illusion that interests me most is counterchange. 
The principle underlying counterchange is that positive and negative shapes (or figure and ground) can be interchanged. Fisher defines figure-ground illusions as "reversible or equivocal relationships in which the mind cannot choose between the positive or negative shapes and shifts attention repeatedly from one area to the other." ${ }^{63}$ A surface design employing figure-ground illusion appears activated, although the movement is really that of the eye as it tries to discern and communicate multiple pattern to the brain. Even when the brain understands the logic of the patterning, it is difficult to freeze the illusion and see it whole: "Quilts of illusion are ambiguous: when the eye is stimulated by shape and line, more than one pattern can easily be seen. The different elements cannot be observed simultaneously; only one shape will predominate at any given moment, varying as our observation is prolonged." ${ }^{64}$

In many blocks, successful counterchange is largely dependent on value, the measure of how light or dark a color appears. One such block is Balkan Puzzle, a variation of which I used in Oops! (see Figure 8). Fisher notes that "this use of reverse or contrasting value also conveys an illusion of movement or space. Even when the light and dark tonal contrasts may not be 'pure,' as in the case of patterns incorporating many different scraps of fabric in related tones, the eye manages to compensate for irregularities in sequence so that the optical effect is carried through." ${ }^{65}$ Relying on the random effects of scrap piecing as I do, I find that maintaining control of value is extremely important. In Mutability, a nine-patch variation that incorporates 52 different handmade papers, I chose to paint kozo with acrylic washes to achieve the dark, jewel tones of the pieces that form the diagonal crosses. The dark values are necessary, not just to make the diagonals visible, but to contrast with the light, overlapping squares that 
appear with the counterchange (see Figure 9). Interestingly, by scrap piecing Out There in Here in an unusual setting by alternating the orientation of the light and mid-range values, I was able to achieve both a strong three-dimensional effect and counterchange (see Figure 10). Depending on where the viewer focuses attention, the pattern appears to depict either windows opening to a deep purple sky or ribbons in alternating light and dark patterns running across a purple background. This was the last piece I decided to include in the exhibit to provide both a more intense illusion of depth and a different sense of scale. The six inch squares of the work, although they contain 3" squares like many other of the works, nonetheless appear to be pieced on a larger scale than other works in the exhibit.

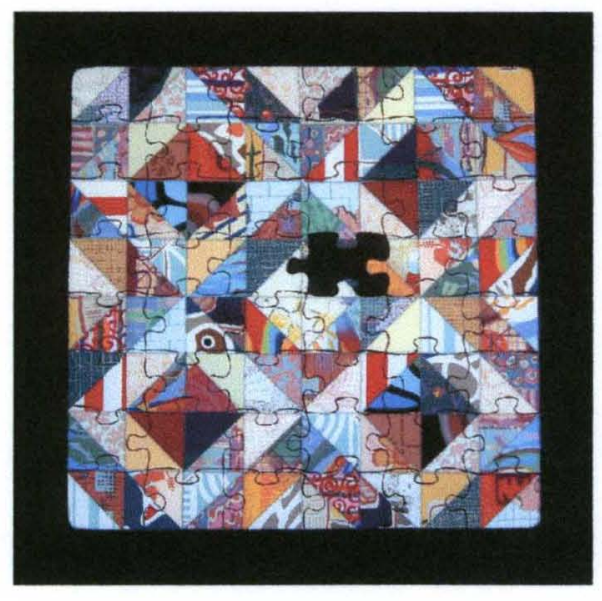

Figure 8: Oops!, 2010

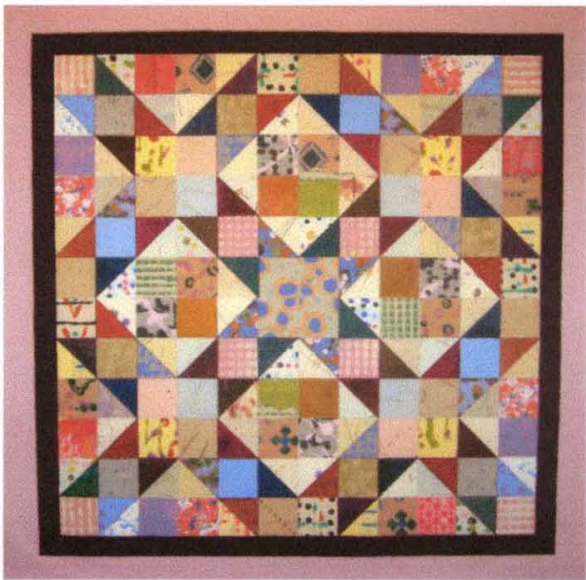

Figure 9: Mutability, 2011

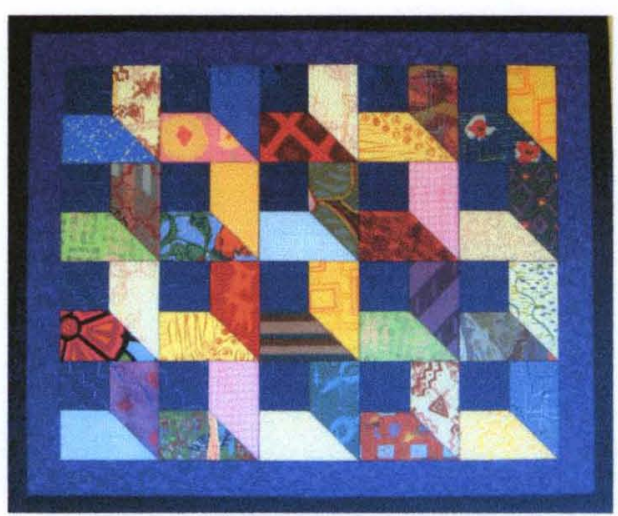

Figure 10: Out There in Here, 2011 


\section{Medium and Method}

Whether I am printing a fifteen color image requiring precise registration with photo-emulsion stencils or a two color image using a temporary soy wax block, layering is an essential part of my screen printing method. I almost never choose to register areas of color side by side, preferring instead to overlap color and build subtle, low-relief texture on the print. Reba and Dave Williams, authors of American Screenprints, point out that in the early practice of screen printing by artists, the temptation to imitate the visual appearance of painting was hard to resist: "Most artists utilized a painterly style of screen printing, with brushstrokes and overlapping, or blurring colors, rather than the flat planes of color so suited to the medium." ${ }^{66}$ While it may still be considered a painterly technique, layering lets me impart visual texture to a print (a technical concern) and explore the concept of time (a philosophical concern). Layers of ink that almost but do not quite occupy the same space simultaneously create a whole image discernable at a glance and make the viewer aware that not everything is revealed. Layers create depth that doesn't depend on geometry, inviting the viewer to engage more fully by entering the world of the image. Layers necessarily imply linear chronology, because the ones on top have to be laid down after the ones on bottom. But they also create the possibility that time - say the span of a human life-- may be more fruitfully portrayed as a spiral, not a straight line, one that recursively allows us to revisit old haunts, but from a slightly different position. Spiraling time admits the idea that we get older and wiser, that memory is enriched with experience yet to come. Layers thus allow me simultaneously to think holistically and sequentially, to consider the dynamic interplay of past, present, and future in one moment. 
When it comes to how I layer color, I use every technique in my repertoire. Screen printing is essentially a stenciling method. Unprotected areas of a screen allow ink to print a positive image when forced through the screen by a squeegee. There are multiple ways to create stencils or blocks that adhere to a screen, ranging from photo emulsion (the most chemically dependent) to wax paper stencils cut with an $\mathrm{x}$-acto knife and taped securely to the back of a screen. These are certainly the two methods I use most often, but I have also experimented with drawing fluid and screen filler, soy wax blocks, heavy-weight pellon stencils that temporarily hold back ink before allowing it to bleed through in interesting but unpredictable ways, dried flour paste that is suitable for multiple prints but can only be used for one color before dissolving, masking tape, crayon, and various pieces of lace or plastic that allow me to print an image or two before becoming fully saturated with ink. The more experienced I become with screen printing as a medium, the more eclectic my methods become.

My palette is determined by the ink I use, primarily Speedball acrylic screen printing ink in hues of medium red, dark red, ultra blue, dark blue, peacock blue, medium yellow, primrose yellow, brown, black, and white. Typically, I alter any ink I use by changing the value, level of intensity, or hue with additives. I mix most secondary colors and tertiary colors by combining primary colors above, although occasionally I will use Speedball violet. Increasingly, I have been working with Jacquard Textile Colors. These inks are designed for screen printing on woven fabrics and work well for that purpose, but I have discovered that I also like the translucency of this kind of ink on paper. Jacquard Textile Colors require heat setting with an iron to permanently affix the ink to textiles, and may not seal a paper surface as well as Speedball inks without applying heat. 
Speedball inks are opaque, although I can render them transparent when I need to by adding transparent base, and they dry with a slight sheen that heat can damage. In fact, too much heat applied to a Speedball ink surface can alter the appearance of the colors, causing some to darken and others to appear more brilliant. Since the completed pieces combine prints rendered with these two different inks, I have learned to be extremely cautious when applying heat to any inked surface.

In addition to ink, I also use Rembrandt Aquarell pencils and Lyra Aquacolor crayons to apply color to the surface of my prints. These materials allow me to draw directly on the screen before printing. Because these pencils and crayons are water soluble, they will release color when I squeegee extender base or transparent color across the screen. Typically, this method of applying color is good for only one or two prints at a time before the color is released. Using these materials means I have to be extremely cautious with water as well as heat. The crayons, in particular, will wash off the printed surface with water, and they can melt and be lifted off the surface with a hot iron.

To color the surfaces of handmade paper I incorporated into Mutability, I used a technique known as pulp painting. Like screen printing, pulp painting has connections to stenciling. I mixed small amounts of overbeaten pulp, usually of linen fiber, with aqueous dispersed pigment and retention agent. After testing to make sure that the pigment was retained and would not bleed into surrounding areas, I applied the colored pulp to the surface of a newly formed, but not yet pressed sheet of paper made from cotton pulp. I did this in various ways: by using stencils registered to create multicolored designs, by free-hand painting (usually with an eye dropper), by pouring or dripping, or by double-couching a free-form, colored pulp design on Mylar to a plain 
base sheet. I then pressed the pulp-painted sheets of paper, bonding the fibers together so that the colored pulp became part of the base sheet. The final result looks much like screen printing.

\section{Image: Pattern and Visual Texture}

A question that interested me when I started to bring together pieces of prints in block designs was how much variety could be introduced into a design without creating visual chaos. I suspected that the basic structure of a block, controlled by the organizing principles of grids and basic geometry, would actually support a high degree of contrast in color, pattern, and visual texture as long as I kept the placement of light and dark values consistent. I decided to test this theory by scrap piecing, a technique that let me take advantage of every print I have made, successful or not. It also gave me the opportunity to learn enough about textile design to develop and print patterns of my own devising.

Pattern, ubiquitous as it is, is not widely written about, but I found some help in Anatomy of Pattern written by Lewis Day in 1887. Published during the Arts and Crafts Movement, the book is a sort of designer's manual, providing classifications of patterns and instructions about how to create them. What I found most interesting, however, was Day's speculation about the origin of pattern. Stating that "pattern mostly comes from repetition," Day goes on to explain that "many a pattern bears on the face of it the evidence that it grew directly out of the necessity for repetition. It is more than probable that some mechanical necessity gave rise to all geometric pattern; certainly it is impossible to plait, net, knit, weave, or otherwise mechanically make, without producing 
pattern." ${ }^{67}$ I like the idea that pattern may be something we internalize through making as well as learn through observing patterns that occur in nature.

For information about how patterns in textile designs repeat, I turned to Carol Joyce's Textile Design. ${ }^{68}$ This book not only explained square and half-drop repeats, the simple methods I began to employ in my own designs, but taught me about colorways, or the practice of rendering designs in different color combinations to test the visual effectiveness of each. These basic techniques particularly informed the images I printed to complete Gala, a work in which the scale alone required more raw material than I had available. I also had to keep the color "families" of that piece visually coherent so much of what I had printed earlier could not be incorporated.

Throughout each pieced work, I tried to balance the regularity of repeated patterns such as stripes, plaids, florals, weaves, dots, and free-form shapes with the more random designs that occurred when I abstracted pieces from printed images that had not been intentional pattern repeats. Scrap piecing creates additional, unexpected interactions between patterns. Where the edges of screen printed paper meet, patterns and colors will blend together or contrast with one another in varying degrees. These relationships alter the pattern of shapes that emerge most prominently from a design, and help create the illusion of depth as some areas appear to recede while others appear to move forward. This enhances the overall visual texture of the piece. The work in which this effect is most prominent is Circle in a Square which brings together four different screen printed patterns in the center of each square in the grid of nine (see Figure 11). 


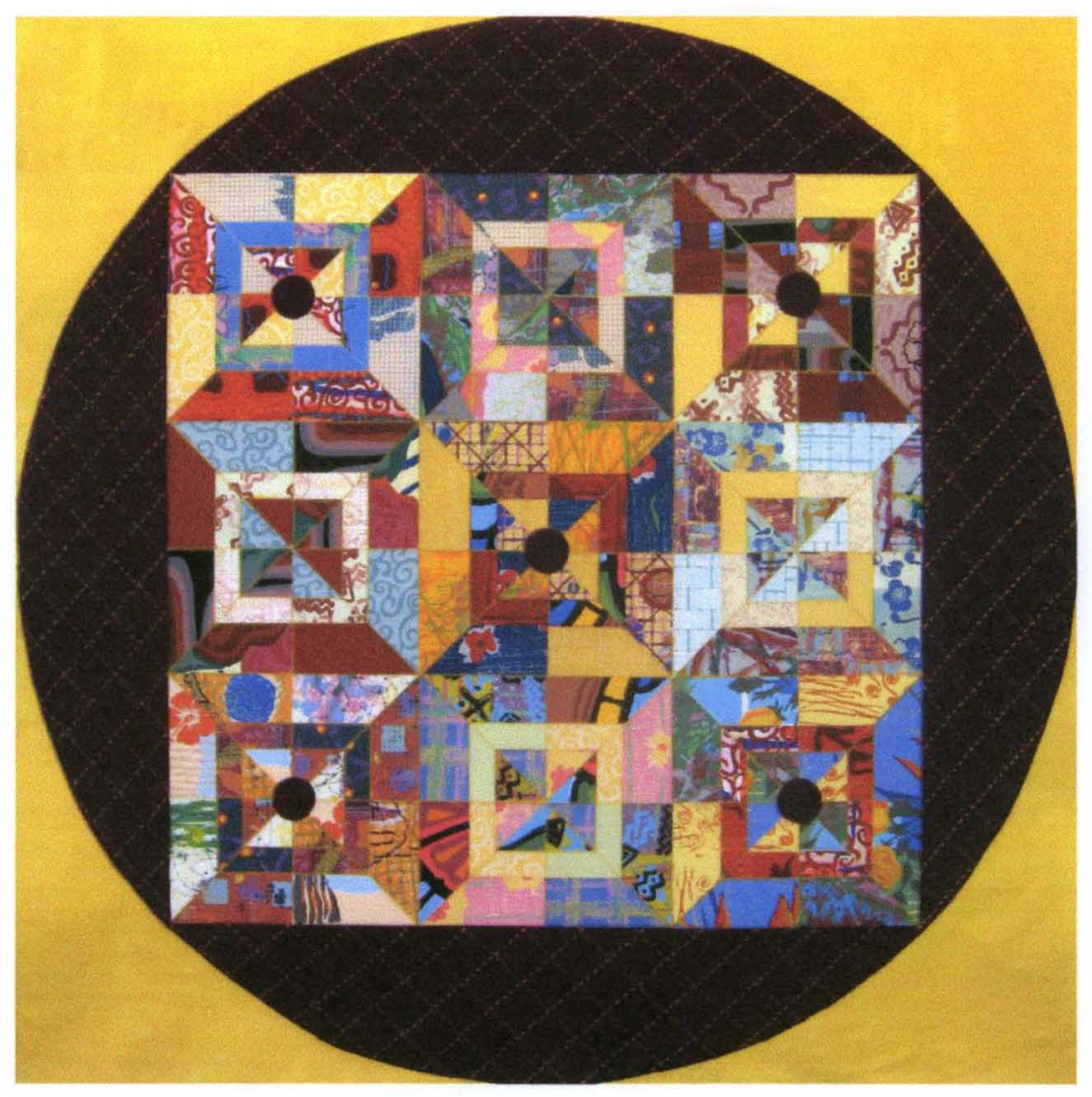

Figure 11: Circle in a Square, 2011

As well as using layering to achieve visual texture in each image I printed, I experimented with the effect of layering on top of a fully pieced work. In Oops!, I did this to see whether the imposed pattern of the puzzle would be legible above the diamonds and squares created by the value shifts in the Balkan Puzzle block. In Summer Days, Summer Nights, I wanted to see if the central, light area, created by rotating the four Log Cabin blocks in different directions, would be a suitable ground for a photo emulsion stencil that I created from an India ink drawing on wax paper (see Figure 12). Although I enjoy the contrast between the spontaneity of the drawing and the precise geometry of the piecing, if I were to try this technique again, I think I would create more definite lines (many are broken because of the way wax paper repels ink) so that the super-imposed image would be more fully rendered. 


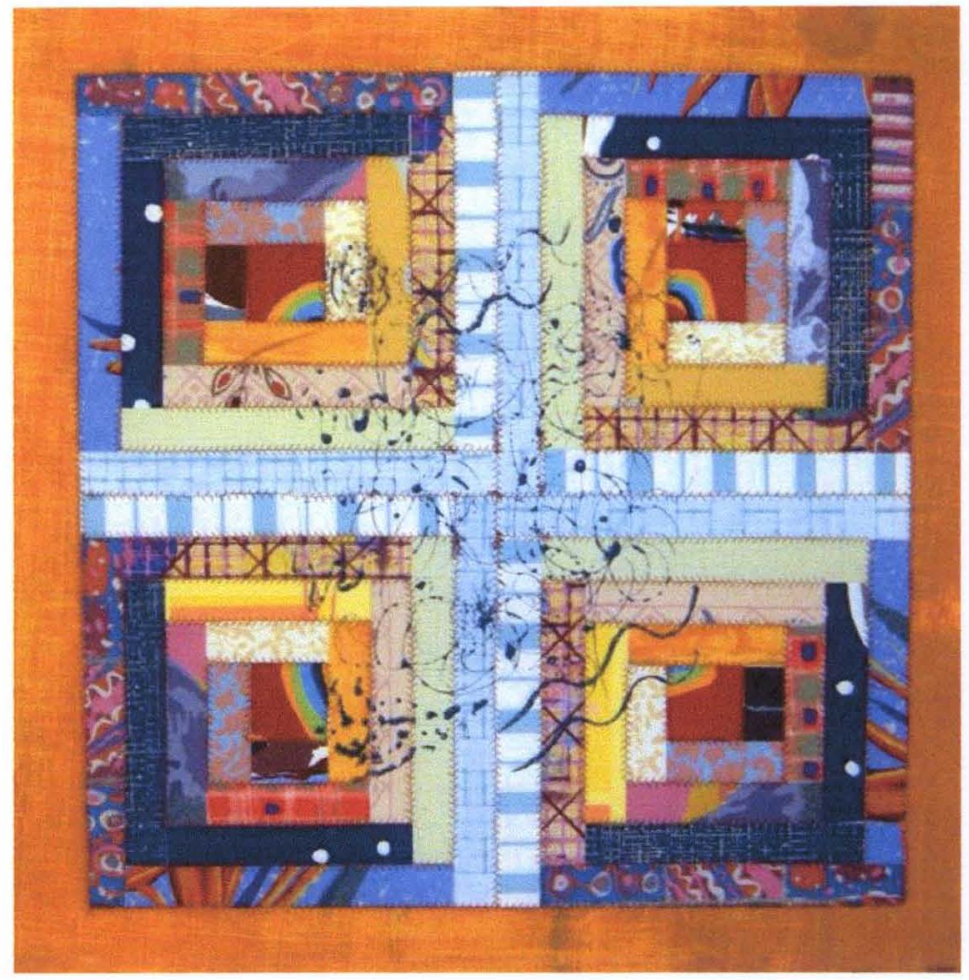

Figure 12: Summer Days, Summer Nights, 2010

\section{Construction}

After resolving matters of design, the next issue, and often the most problematic, was to figure out how to put pieced blocks together to achieve the scale of the final works. I increased scale gradually; my initial pieced works were small (generally 24 " x 24") and did not pose the same difficulties of a work like Gala (54" x72"). A summary of the construction process would be: first, to cut and arrange the required geometric shapes in enough quantity to construct the blocks necessary to reach the desired dimensions; second, to adhere the pieces with small amounts of archival glue to a base sheet of paper (either plain or screen-printed with one of the colors or patterns that make up the final design) to create blocks; third, to join the edges of the pieces together with zig-zag or other decorative machine-stitching; fourth, to glue or tape completed blocks together and join their edges with machine-stitching; fifth, to support the piece by 
securing iron-on pellon to the reverse side or alternatively, using Mistyfuse (another fusible product) to attach the joined paper blocks to painted canvas or other commercially dyed fabric suitable for mounting on stretcher bars.

The first step, piecing, involved cutting geometric shapes precisely enough so that the points would match throughout the joining process ensuring that the whole piece would come together in square. How the pieces were oriented in relation to one another determined whether I could stitch along straight horizontal or vertical lines or have to contend with diagonals. Diagonal lines were difficult to stitch because the amount of paper I had to maneuver through the sewing machine grew larger as a line approached the center of an area. This variation put more stress on some lines of stitching than others, causing them to tear along the evenly spaced perforations left by the needle. There are many instances where I had to reinforce torn areas from behind with tape or glued paper patches and then conceal the repair with additional surface stitching.

Although most of the works in the exhibit use traditional block piecing to create the overall effect, two do not, and they each presented construction problems unique to their design. The first is Circle in a Square based on an original design that I discovered while experimenting with the effects of scrap-pieced stripes. The original piecing was in stripes of different patterns running horizontally on 5 " $\times 10$ " rectangles. I then cut the rectangles into five-inch squares and bisected each diagonally in opposite directions. When I began to rotate the triangular pieces, I found that I could bring what had been a one-inch stripe together to create the square lines that appear to float above the surface of juxtaposed patterns. This was a serendipitous result: suddenly, stripes were out and squares were in. The piecing brought together eight triangles composed of three patterns 
in the center of nine ten-inch squares. To my dismay, I discovered that hardly any of the points came together properly. Some central areas joined more accurately than others or could be adjusted; others needed to be disguised. This is why I applied fabric circles to the center of five squares. Once the circles were secured, it seemed like an interesting idea to attach the joined squares to a fabric circle with the ultimate intent of attaching the circle to a painted canvas that would be mounted on square stretcher bars. Of all the works in the exhibit, this is the one that required the most time because I decided to soften the sharp contrast in value between the fabric circle and canvas behind it by quilting the circle with two colors of hand stitching. I take secret pleasure in the fact that the work with the least traditional design is the only one in the show to include actual quilting.

The other work that is pieced differently from most is Gala. I was working on a design based on large diamonds, thinking that I would screen print four elaborate patterns to form different quadrants of six or eight diamonds. While I was developing this idea, I came across Kaffe Fassett's Simple Shapes, Spectacular Quilts which includes a design for a quilt made from Fassett's textiles called Facet. ${ }^{69}$ Seeing this design changed my construction method entirely. Instead of screen printing and juxtaposing large areas of uniform pattern, I decided to imitate the effect of strip piecing, a method that joins lots of strips of different fabric together before cutting out the whole shape. The effect of the whole depends on keeping the average hue and value of each color family consistent while at the same time including multiple patterns and contrasting elements. When I decided to piece this way, I knew that I had neither enough prints in the right colors nor 
enough time to print all that I would need to finish the work quickly. At that point, I chose to introduce commercially printed fabrics into the piecing (see Figure 13).

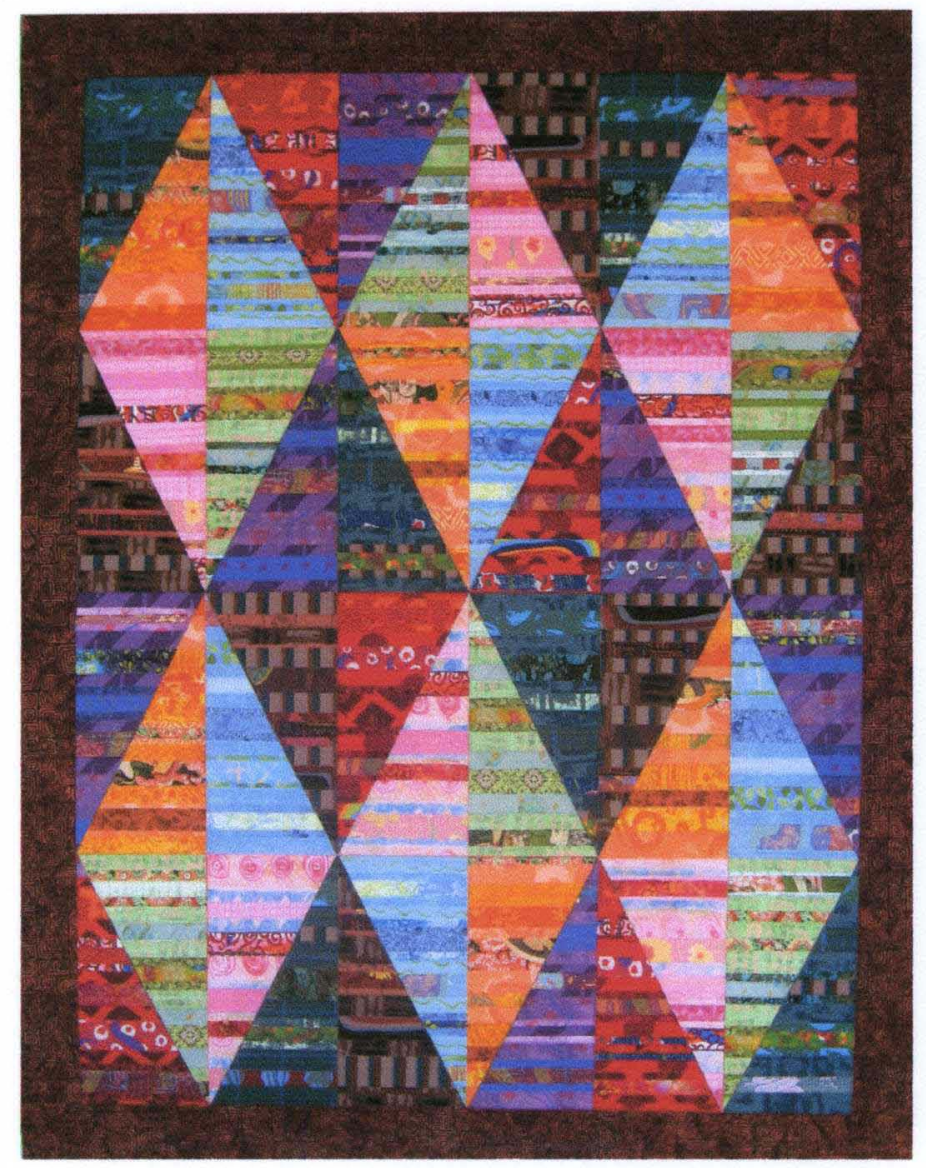

Figure 13: Gala, 2011

The final decision I make about any piece is whether or not to include a border and if so, how wide to make it. All patterns imply infinite expansion, although movement in all directions may not be predictable from the way a given pattern is repeated. Borders provide a boundary at which the pattern stops and beyond which it is difficult to imagine the pattern resuming; thus, borders contain the viewer's attention within the central space of the image. Borders not only eliminate the visual distraction of trying to follow the expansion of multiple patterns in many different directions, they provide a place of quiet contrast to the highly activated surfaces. Some pieces, like 
Mutability, contained so much visual play in the interaction of different patterns that a double border, related to the central image through color and value, felt compositionally necessary. Adding borders also resolved small technical problems by giving me a way to square up overall compositions and disguise any piecing adjustments at the edges. The only piece without a border is Gone Awry. I purposely matched the size of the composition without a border to the size of the stretcher bars after stitching it to untreated canvas. My intent was to encourage the viewer to follow the asymmetrical lines of each quadrant to the edges and puzzle over how the pattern might continue if it were to expand. To continue, the diagonal lines of the pattern would have to cross one another, and it is extremely difficult to imagine the geometry of the squares where that might happen. In this case, I chose to let the edges stimulate the viewer rather than serve as a space of visual rest. 


\section{CONCLUSION}

In The Natural History of the Traditional Quilt, authors John Forest and Deborah Blincoe emphasize their purpose to "lay out a system by which the quilt can be seen at the center of its own nexus of relationships. The decision to stay with the quilt, letting it generate its own method of investigation through the facts of its existence, yields a final

image of traditional quilts and quiltmaking which is as free as possible from distortion." 70 Visually, I have attempted something similar in this thesis by exploring those aspects of design that seemed most to urge themselves forward when I began to look at traditional quilt blocks. These features include reliance on the grid, the illusionary optical effect of counterchange, and the activating powers of pattern juxtaposition.

Visual references to the quilt, however, communicate as much about history as they do about design. One inescapable relationship the quilt maintains is to feminist art of the 1970s and to the women today who continue to develop the genre of the art quilt. It has been rewarding to me, as a woman and an artist, to find inspiration in the words, work, and company of other women. That I have been able to do so easily suggests that the art world and its history are evolving to become more inclusive and less rigid about confining definitions. As Malcolm McCullough states, "Pure art has endless definitions. For example, Paul Klee said the purpose of art is to awaken reality. But relative to craft, we can say that art is the creation of artifacts for indescribable, not preconceived, and possibly impractical ends: to search, to reveal, to release." ${ }^{71}$ Echoing Linda Nochlin, I would define my experience with art as a challenging kind of patchwork liberation. 


\section{NOTES}

${ }^{1}$ Brenda Danilowitz, ed. Annie Albers: Selected Writings on Design (Hanover: University Press of New England, 2000), 36-37.

2 Jane Dunnewold, "Art Quilts: Emerging Genres,"

http://existentialneighborhood.blogspot.com, retrieved 2/06/11.

3 Patricia Mainardi, "Quilts: The Great American Art," Feminism and Art History, Ed. Norma Broude and Mary D. Garrard (New York: Harper and Row, 1982) 331.

Originally published in The Feminist Art Journal v. 2 no. 1 (Winter 1973): 1-22.

${ }^{4}$ Mainardi 337.

${ }^{5}$ Mainardi 344.

${ }^{6}$ Mainardi 344.

${ }^{7}$ Lucy Lippard, "Up, Down, and Across: A New Frame for New Quilts," The Artist and the Quilt, Ed. Charlotte Robinson (New York: Alfred A. Knopf, 1983) 32.

${ }^{8}$ Lippard 32.

${ }^{9}$ Lippard 32.

${ }^{10}$ Lippard 33 .

${ }^{11}$ Lippard 32.

${ }^{12}$ Miriam Schapiro, "Geometry and Flowers," The Artist and the Quilt, Ed. Charlotte Robinson (New York: Alfred A. Knopf, 1983) 26.

${ }^{13}$ Norma Broude, "Miriam Schapiro and 'Femmage': Reflections on the Conflict between Decoration and Abstraction in Twentieth-Century Art," Feminism and Art History: Questioning the Litany, Eds. Norma Broude and Mary D. Garrard (New York: Harper and Row, 1982) 320.

${ }^{14}$ Schapiro 29. 
${ }^{15}$ www.thedreamrocket.com, retrieved 12/09/09.

${ }^{16}$ Schapiro 26.

${ }^{17}$ Schapiro 29.

${ }^{18}$ Dunnewold, “Art Quilts," retrieved 2/06/11.

19 Susan Bernick, “A Quilt Is an Object When It Stands Up Like a Man," Quilt Culture: Tracing the Pattern, Eds. Cheryl B. Torsney and Judy Elsley (Columbia: University of Missouri Press, 1994) 135.

${ }^{20}$ Michael James, "The Art Quilt: A Critical Perspective," Surface Design, Fall 2010 (Volume 35, Issue 1): 10.

${ }^{21}$ Rozsika Parker and Griselda Pollock, Old Mistresses (New York: Pantheon Books, 1981) 50 .

22 Ann Newdigate, "Kinda Art, Sorta Tapestry," New feminist art criticism, Ed. Katy Deepwell (Manchester: Manchester University Press, 1995) 181.

23 Dunnewold, “Art Quilts," retrieved 2/06/11.

${ }^{24}$ Lippard 43

${ }^{25}$ Lippard 43.

${ }^{26}$ Broude 322.

${ }^{27}$ Janet Catherine Berlo, "The Artist and Her Domestic Muse: May Sarton, Miriam Schapiro, Audrey Flack," That Great Sanity, Ed. Susan Swartzlander and Marilyn Mumford (Ann Arbor: University of Michigan Press, 1992) 89.

28 Tamar Garb, “Engaging Embroidery," Art History (1986): 132.

${ }^{29}$ Donald Kuspit, "Betraying the Feminist Intention: The Case Against Feminist Decorative Art," Arts Magazine (November 1979): 124.

${ }^{30}$ Kuspit 125.

${ }^{31}$ Alexandra Anderson-Spivy, Robert Kushner: Gardens of Earthly Delight (New York: Hudson Hills Press, 1997) 7. 
${ }^{32}$ Linda Nochlin, "Miriam Schapiro: Recent Work," Arts Magazine (November 1973), reprinted in Thalia Gouma-Peterson, Miriam Schapiro: Shaping the Fragments of Art and Life (New York: Harry N. Abrams, 1999) 11.

${ }^{33}$ Janet Catherine Berlo, Wild By Design (Lincoln, NE: International Quilt Study Center, 2003) 7 .

${ }^{34}$ Nochlin 11.

${ }^{35}$ Elissa Auther, String, Felt, Thread (Minneapolis: University of Minnesota Press, 2010) 135.

36 Anni Albers, "Work With Material," College Art Journal v.3 no. 2 (January 1944): 52.

${ }^{37}$ Virginia Gardner Troy, Anni Albers and Ancient American Textiles (Aldershot: Ashgate Publishing, 2002) 161.

${ }^{38}$ Malcolm McCullough. Abstracting Craft (Cambridge, MA: MIT Press, 1996) 1.

${ }^{39}$ McCullough 3.

40 Hannah Higgins, The Grid Book (Cambridge, MA: MT Press, 2009) 257.

41 The Woven and Graphic Art of Anni Albers (Washington D.C.: Smithsonian Institution Press, 1985) 130.

42 Danilowitz 58-59.

43 Danilowitz 68.

44 Virginia Gardner Troy, The Modernist Textile (Burlington, VT: Lund Humphries, 2006) 94 .

45 Smithsonian, Cooper-Hewitt National Design Museum, "Color Moves: Art and Fashion by Sonia Delaunay," http://www.cooperhewitt.org/exhibitions/color-moves/, retrieved $3 / 21 / 11$.

${ }^{46}$ Stanley Baron. Sonia Delaunay ( New York: Harry Abrams, 1995) 30.

${ }^{47}$ For more information, see Linda Parry, Textiles of the Arts and Crafts Movement (London: Thames and Hudson, 1988), Angela Volker, Textiles of the Wiener Werkstätte (London: Thames and Hudson, 1994), and Geoffrey Rayner, Artists' Textiles in Britain 1945-1970 (Woodbridge, Suffolk: Antique Collectors' Club, 2003). 
${ }^{48}$ Susan Meller, Textile Designs (New York: Abrams, 1991) 13.

${ }^{49}$ Meller 13.

${ }^{50}$ Mary Schoeser, World Textiles: A Concise History (London: Thames and Hudson, 2003) 111.

51 Schoeser 183.

52 Schoeser 175.

53 Meller 14.

${ }^{54}$ Celia Eddy, The Quilter's Block Bible (New York: Chartwell Books, Inc., 2003) 8.

55 Celia Eddy, Quilting Illusions (London: Quarto Publishing, 2004) 6.

56 Patricia Sloane, The Visual Nature of Color (New York, N.Y.: Design Press, 1989) 148.

${ }^{57}$ Sloane 146.

${ }^{58}$ Sloane 147.

59 Sloane 151.

${ }^{60}$ Laura Fisher, Quilts of Illusion (Pittstown, N.J.: The Main Street Press, 1988) 25.

61 Fisher 42-43.

${ }^{62}$ Fisher 39.

63 Fisher 29.

${ }^{64}$ Fisher 23.

65 Fisher 35.

${ }^{66}$ Reba and Dave Williams, American Screenprints (New York: National Academy of Design, 1987) 16.

${ }^{67}$ Louis Foreman Day, The Anatomy of Pattern (London: B.T. Batsford, 1887) 2.

${ }^{68}$ Carol Joyce, Textile Design (New York: Watson-Guptill, 1993). 
${ }^{69}$ Kaffe Fasset, Simple Shapes, Spectacular Quilts (New York: Abrams, 2010) 106.

${ }^{70}$ John Forrest and Deborah Blincoe, The Natural History of the Traditional Quilt (Austin: University of Texas Press, 1995) 207.

${ }^{71}$ McCullough 20. 


\section{REFERENCES}

Albers, Anni. "Work with Material," College Art Journal iii (January 1944): 51-4.

---. The Woven and Graphic Art of Anni Albers. Washington D.C.: Smithsonian Institution Press, 1985.

Anderson-Spivy, Alexandra. Robert Kushner: Gardens of Earthly Delight. New York: Hudson Hills Press, 1997.

Auther, Elissa. String, Felt, Thread. Minneapolis: University of Minnesota Press, 2010.

Baron, Stanley. Sonia Delaunay. New York: Harry Abrams, 1995.

Berlo, Janet Catherine. "The Artist and Her Domestic Muse: May Sarton, Miriam Schapiro, Audrey Flack." That Great Sanity. Eds. Susan Swartzlander and Marilyn Mumford. Ann Arbor: University of Michigan Press, 1992. 85-108.

..-. Wild by Design. Lincoln: NE: International Quilt Study Center, 2003.

Bernick, Susan. "A Quilt Is an Object When It Stands Up Like a Man." Quilt Culture: Tracing the Pattern. Eds. Cheryl B. Torsney and Judy Elsley. Columbia, MO: University of Missouri Press, 1994. 134-150.

Broude, Norma. "Miriam Schapiro and 'Femmage': Reflections on the Conflict between Decoration and Abstraction in Twentieth-Century Art." Feminism and Art History: Questioning the Litany. Eds. Norma Broude and Mary D. Garrard. New York: Harper and Row, 1982. 315-328.

Danilowitz, Brenda, ed. Annie Albers: Selected Writings on Design. Hanover, N.H.: Wesleyan University Press, 2000.

Day, Louis Foreman. The Anatomy of Pattern. London: B.T. Batsford, 1887.

“The Dream Rocket." 9 December 2009. http://www.thedreamrocket.com.

Dunnewold, Jane. “Art Quilts: Emerging Genres." 4 Feb. 2011.

http://existentialneighborhood.blogspot.com.

Eddy, Celia. The Quilter's Block Bible. New York: Chartwell Books, Inc.,2003. 
---. Quilting Illusions. London: Quarto Publishing, 2004.

Fasset, Kaffe. Simple Shapes, Spectacular Quilts. New York: Abrams, 2010.

Fisher, Laura. Quilts of Illusion. Pittstown, N.J.: The Main Street Press, 1988.

Forrest, John and Deborah Blincoe. The Natural History of the Traditional Quilt. Austin: University of Texas Press, 1995.

Garb, Tamar. "Engaging Embroidery." Art History (1986): 131-134.

Higgins, Hannah. The Grid Book. Cambridge, MA: MIT Press, 2009.

James, Michael. "The Art Quilt: A Critical Perspective." Surface Design 35 (Fall 2010): 6-11

Joyce, Carol. Textile Design. New York: Watson-Guptill, 1993.

Kuspit, Donald. "Betraying the Feminist Intention: The Case Against Feminist Decorative Art." Arts Magazine 54 (November 1979): 124-126.

Lippard, Lucy. "Up, Down, and Across: A New Frame for New Quilts." The Artist and the Quilt. Ed. Charlotte Robinson. New York: Alfred A. Knopf, 1983. 32-39.

Mainardi, Patricia. "Quilts: The Great American Art." Feminism and Art History. Eds. Norma Broude and Mary D. Garrard. New York: Harper and Row, 1982. 331346.

Meller, Susan. Textile Designs. New York: Abrams, 1991.

McCullough, Malcolm. Abstracting Craft. Cambridge, MA: MIT Press, 1996.

Newdigate, Ann. "Kinda Art, Sorta Tapestry." New Feminist Art Criticism. Ed. Katy Deepwell. Manchester: Manchester University Press, 1995. 174-181.

Nochlin, Linda. "Miriam Schapiro: Recent Work." Miriam Schapiro: Shaping the Fragments of Art and Life by Thalia Gouma-Peterson. New York: Harry N. Abrams, 1999. 7-12.

Parker, Rozsika and Griselda Pollock. Old Mistresses. New York: Pantheon Books, 1981.

Parry, Linda. Textiles of the Arts and Crafts Movement. London: Thames and Hudson, 1988.

Rayner, Geoffrey. Artists' Textiles in Britain 1945-1970. Woodbridge, Suffolk: Antique Collectors' Club, 2003. 
Schapiro, Miriam. "Geometry and Flowers." The Artist and the Quilt. Ed. Charlotte Robinson. New York: Alfred A. Knopf, 1983. 26-31.

Schoeser, Mary. World Textiles: A Concise History. London: Thames and Hudson, 2003.

Sloane, Patricia. The Visual Nature of Color. New York: Design Press, 1989.

Smithsonian Cooper-Hewitt Design Museum. "Color Moves: Art and Fashion by Sonia Delaunay." 21 March 2011. http://www.cooperhewitt.org/exhibitions/colormoves.

Troy, Virginia Gardner. Anni Albers and Ancient American Textiles. Aldershot:Ashgate Publishing, 2002.

---. The Modernist Textile. Burlington, VT: Lund Humphries, 2006.

Volker, Angela. Textiles of the Wiener Werkstätte. London: Thames and Hudson, 1994.

Williams, Reba and Dave Williams. American Screenprints. New York: National Academy of Design, 1987. 


\section{CURRICULUM VITAE}

NAME:

ADDRESS:

DOB:

EDUCATION

\& TRAINING:
Gweneth Anne Dunleavy

2304 Northfield Drive

Louisville, KY 40222

Peoria, Illinois - April 19, 1954

B.A., English

Carleton College

1972-1976

M.A., English

University of Illinois at Urbana-Champaign

1978-1980

Papermaking

Penland School of Crafts

2010

AWARDS: $\quad$ Provost's Award for Exemplary Advising

University of Louisville, 1995-96

PROFESSIONAL

SOCIETIES:

JURIED

EXHIBITIONS: $\quad$ Spring into Art, Jeffersonville, IN

2009, 2010, 2011

Bluegrass Biennial, Morehead, KY

2010

LAFTA Exhibit, Louisville, KY

2011 